\title{
Performance Analysis of Solar Box Cooker
}

\author{
Ravisankar T \\ Asst. Professor Dept. of mechanical Engineering, Kongu \\ Engineering College, Erode, \\ Tamilnadu, India \\ Angappan S \\ Student, Dept. of mechanical Engineering, Kongu \\ Engineering College, Erode, \\ Tamilnadu, India
}

\author{
Dinesh K \\ Student, Dept. of mechanical Engineering, Kongu \\ Engineering College, Erode, \\ Tamilnadu, India \\ Dharmaraj K \\ Student, Dept. of mechanical Engineering, Kongu \\ Engineering College, Erode, \\ Tamilnadu, India
}

\begin{abstract}
The project is about the utilization of solar energy for domestic purpose. Conventional cooking process is more expensive process. It requires more consumption of conventional fuels. But utilizing solar energy, we can minimize the fuel usage and also minimize our expense. In this project, we make use of mirrors to obtain the heat energy from the sunlight. By constructing a box cooker, having mirrors pieces pasted over its extended surface area, we can achieve the heat energy. When the sun radiation falls on the box, the mirror reflectors reflect the rays to the focal point of the box. By placing the cooking vessel in the focal point, we can cook the food. Also, we are going to analyse the different surface thermal performances with coated and non-coated. By this we can obtain the maximum temperature for cooking in different materials. This project can be implemented in rural and hilly regions where the cooking energy resources are not properly available.
\end{abstract}

Keywords-Solar cooker, Performance analysis of cooker, reflecting mirror, bx type

\section{INTRODUCTION}

Cooking is the most important energy consuming operation in the domestic sector, as energy for cooking accounts for $50 \%$ of the total primary energy consumption. As solar energy is renewable and not associated with any environmental and health problems, it could be used as a source of thermal energy for cooking. The inner walls and bottom of cooker box to be used for making solar cooker are painted black to increase absorption of heat. It is more suitable for sun shine areas and its low price makes it very attractive commercially, especially among the rural population in the developing countries. The walls of the box are made thick so as to minimize loss of heat due to radiation and is painted all black from inside.

Solar cookers with having an additional energy of phase change material will help to trap more amount of solar energy for a long period of time during the evening conditions. The solar box cooker have aluminum cooking vessel which will increase the rate of heat addition and thus cooking is made fast also the vessels which having glass covering absorber plate will provide the closed volume of air which makes the surrounding of the vessel becomes more heat and performance rate of the box cooker is improved.

\section{THERMAL ENERGY STORAGE}

TES (Thermal Energy Storage) could be a important technology in systems involving renewable energies further as different energy resources because it will build their operation additional economical, significantly by bridging the amount between periods once energy is harvested and periods once it's required. These demands is matched with the assistance of thermal energy storage systems that operate synergistically, and deals with the storage of energy by cooling, heating, melting, curing or vaporizing a fabric and also the thermal energy becomes obtainable once the method is reversed.

\section{COMPONENTS OF BOX TYPE SOLAR COOKER \\ 3.1 Outer Box}

The outer box of a box type solar cooker is designed with specific dimensions $2 \times 1 \times 1$ (in feet units). It is designed with the help of Catia software and fabricated by plywood and the reflector doors are joined by using rectangular hinges.

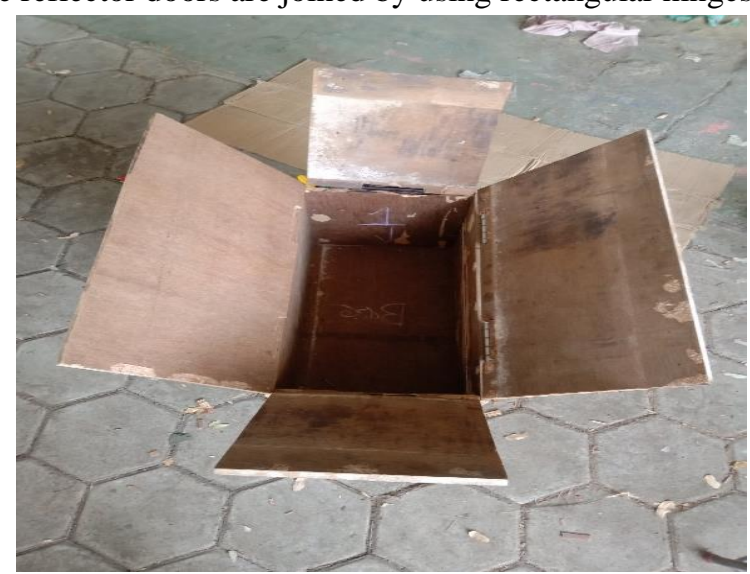

Fig 3.1 Outer box

\subsection{Glass lid}

The main function of the plane glass is to provide the air tightened closed space for cooking and acts as an inner box. It is place at the top of the outer box and supported by using wooden beadings on the sides of the outer box.

3.3 Mirror Reflector

Reflector acts as a source of providing heat to the box cooker by reflecting the sunlight which falls on their mirrored surface inclined at some angle. The inclination of the reflector plays an important role in this cooker because the sun 
radiation reaching the earth's surface at an angle needs to be diverted into the solar box cooking vessel. This reflector is placed at inclination angle by means of stainless-steel hooks which is screwed in the surface of outer box.

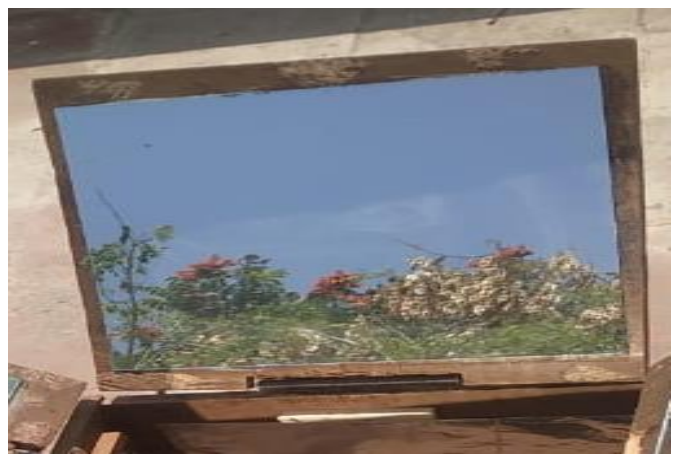

Fig 3.2 Mirror Reflector

\subsection{Phase Change Material}

Phase change material changes it state from one form to another by maintain the process of heat addition and rejection to the substance. Paraffin wax is a kind of material which changes into solid when heat is liberated from the substance and changes into liquid when heat is added to them and this happens until phase change capacity of material remains in it.

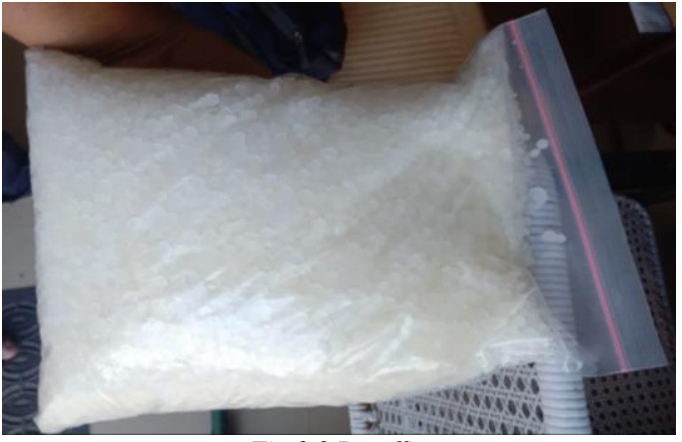

Fig 3.3 Paraffin wax

\subsection{Cooking vessel}

The cooking pot with glass lid is more suitable for solar cooking because the air tightened lid will help to increase the cooking rate. It is mainly manufactured by stainless steel, because it is safe and durable and glass lid retains more heat. It permits cooking process to be observed through glass without lifting lid.

\subsection{Temperature sensors}

Temperature sensors are going to used in this project to measure the temperature of solar cooker. Thermocouple is used and it's principle is seebeck effect which says that two
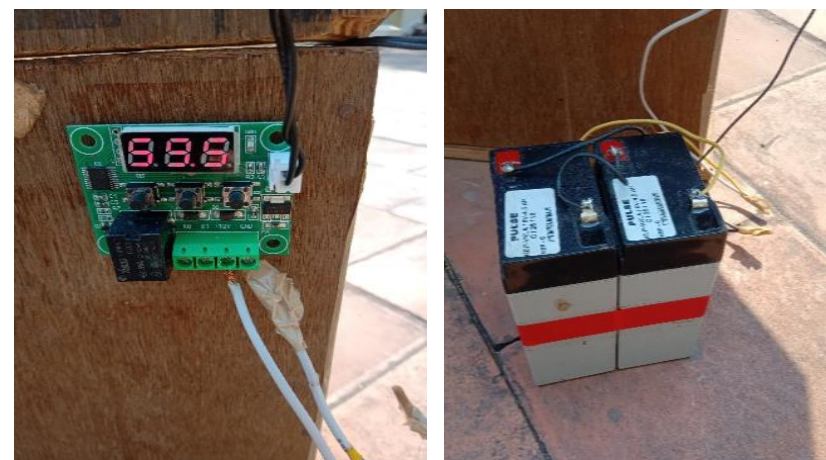

Fig 3.4 Temperature sensor and battery dissimilar metal wires are connected in two different temperatures hot and cold junction and emf is generated which measures the change in temperature.

\section{4 .CONSTRUCTION AND ASSEMBLY OF THE COMPONENTS}

This is to describe the detailed construction procedure of the solar box cooker. It consists of three section; the wooden box frame, the mirror reflector and the Aluminium foil with PCM. The construction of the solar box cooker, based on the initial design sketches, materials were brought, in which the detail explanation are given below:

Aluminum foil of (2 pieces) $30 \mathrm{~cm} \times 60 \mathrm{~cm}$ and $(2$ pieces $)$ $30 \mathrm{~cm} \times 30 \mathrm{~cm}$ with $2 \mathrm{~mm}$ thickness were fixed. The wooden box frames were to be made with the plywood materials ( 2 pieces) $60 \mathrm{~cm} \times 30 \mathrm{~cm} \times 30 \mathrm{~cm}$ and $(2$ pieces) $30 \mathrm{~cm} \times 30 \mathrm{~cm} \times$ $30 \mathrm{~cm}$. The stone pebbles, phase change materials and cooking vessel were kept inside the wooden box. The plywood pieces can be connected with nail, hinges and hook The mirror reflector with dimensions of $28 \mathrm{~cm} \times 58 \mathrm{~cm}$ was used as the emitting radiation where the mirror piece is glued. An Aluminium foil absorber helps to cooking vessel was placed in the box when cooking.

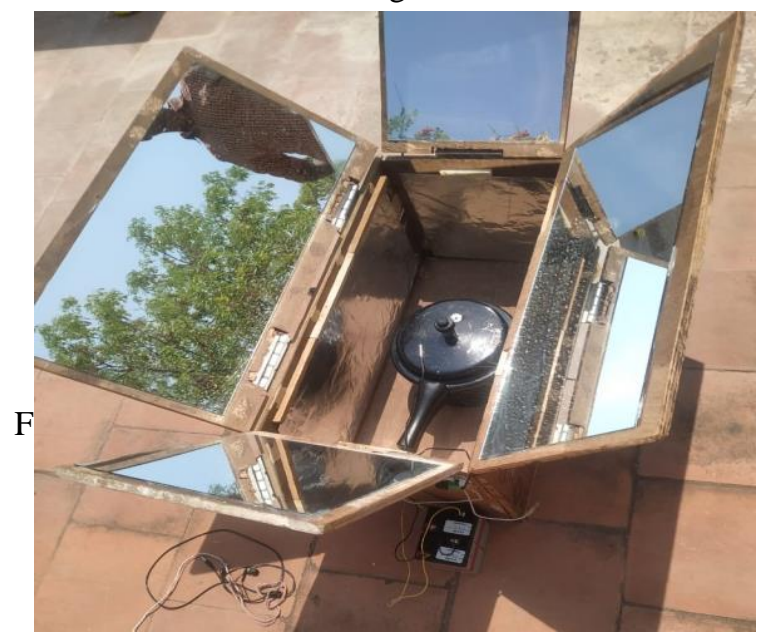

Fig 4.1 Solar box cooker

\section{EXPERIMENTAL READINGS}

5.1 TEMPERATURE OF BLACK COATED PRESSURE

\section{COOKER}

The following table 5.1 shows the temperature readings of the black coated pressure cooker. The temperature is measured by keeping the water inside the black coated cooker. The measured temperature is plotted versus time.

Table 5.1 Black coated pressure cooker temperature readings 


\begin{tabular}{|c|c|c|}
\hline S.NO & TIME $(\mathbf{m i n})$ & TEMPERATURE( $\left.{ }^{\circ} \mathrm{C}\right)$ \\
\hline $\mathbf{1 .}$ & $1: 50 \mathrm{PM}$ & 40.1 \\
\hline $\mathbf{2 .}$ & $2: 00 \mathrm{PM}$ & 46.9 \\
\hline $\mathbf{3 .}$ & $2: 10 \mathrm{PM}$ & 49.7 \\
\hline $\mathbf{4 .}$ & $2: 20 \mathrm{PM}$ & 52.2 \\
\hline $\mathbf{5 .}$ & $2: 30 \mathrm{PM}$ & 55.0 \\
\hline $\mathbf{6 .}$ & $2: 40 \mathrm{PM}$ & 61.1 \\
\hline $\mathbf{7 .}$ & $2: 50 \mathrm{PM}$ & 65.3 \\
\hline $\mathbf{8 .}$ & $3: 00 \mathrm{PM}$ & 69.2 \\
\hline $\mathbf{9 .}$ & $3: 10 \mathrm{PM}$ & 76.0 \\
\hline $\mathbf{1 0 .}$ & $3: 20 \mathrm{PM}$ & 78.5 \\
\hline
\end{tabular}

\section{TIME VS TEMPERATURE}

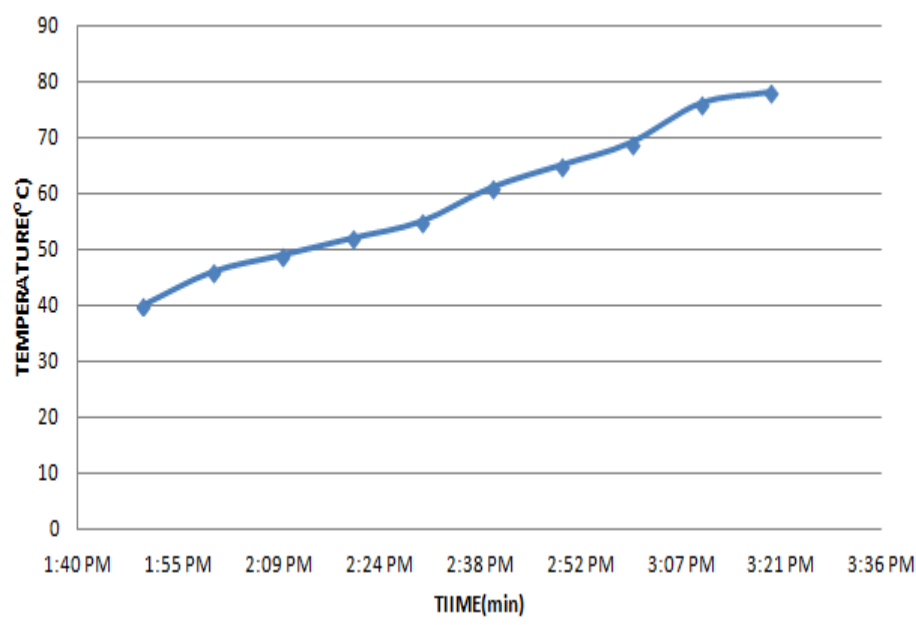

Fig 5.1 Time vs Temperature of black coated pressure cooker

\subsection{TEMPERATURE OF COOKER WITH PARAFFIN} WAX AND STONE PEBBLES

The following Table 5.2 shows the temperature readings of the phase change material (paraffin wax) with stone pebbles. The temperature is measured by keeping the water inside the PCM (Paraffin wax) with stone pebbles.

Table 5.2 Pressure cooker with paraffin wax and stone pebbles

\begin{tabular}{|c|c|c|}
\hline S.NO & TIME $(\mathbf{m i n})$ & TEMPERATURE $\left({ }^{\circ} \mathbf{C}\right)$ \\
\hline $\mathbf{1 .}$ & $1: 40 \mathrm{PM}$ & 55.2 \\
\hline $\mathbf{2 .}$ & $2: 00 \mathrm{PM}$ & 65.3 \\
\hline $\mathbf{3 .}$ & $2.20 \mathrm{PM}$ & 66.4 \\
\hline $\mathbf{4 .}$ & $2: 40 \mathrm{PM}$ & 69.8 \\
\hline $\mathbf{5 .}$ & $3.00 \mathrm{PM}$ & 73.8 \\
\hline $\mathbf{6 .}$ & $3.20 \mathrm{PM}$ & 79.1 \\
\hline $\mathbf{7 .}$ & $3.40 \mathrm{PM}$ & 84.0 \\
\hline $\mathbf{8 .}$ & $4: 00 \mathrm{PM}$ & 89.1 \\
\hline $\mathbf{9 .}$ & $4: 20 \mathrm{PM}$ & 90.1 \\
\hline $\mathbf{1 0 .}$ & $4: 30 \mathrm{PM}$ & 92.7 \\
\hline $\mathbf{1 1 .}$ & $4: 50 \mathrm{PM}$ & 94.1 \\
\hline
\end{tabular}

TIME VS TEMPERATURE

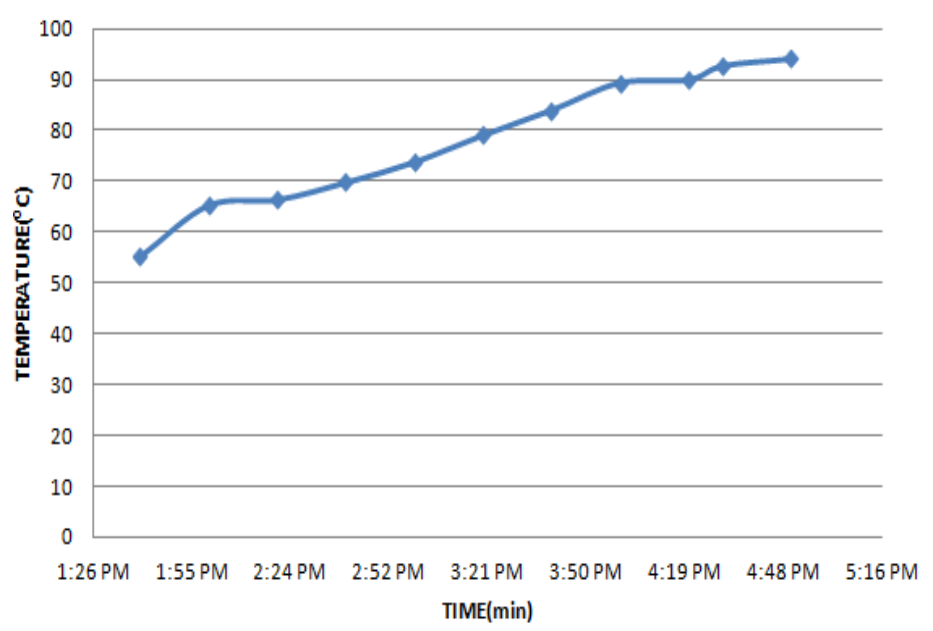

Fig 5.2 Time vs Temperature of black coated cooker with paraffin wax and stone pebbles

\subsection{TEMPERATURE OF BLACK COATED COOKER} WITH PARAFFIN WAX

The following Table 5.3 shows the temperature readings of the black coated pressure cooker with PCM. The temperature is measured by keeping the water inside the black coated pressure cooker with PCM.

Table 5.3 Black coated cooker Temperature with paraffin wax as phase change material 


\begin{tabular}{|c|c|c|}
\hline S.NO & TIME $(\mathbf{m i n})$ & TEMPERATURE $\left({ }^{\circ} \mathbf{C}\right)$ \\
\hline $\mathbf{1 .}$ & $1: 40 \mathrm{PM}$ & 47.2 \\
\hline $\mathbf{2 .}$ & $1: 50 \mathrm{PM}$ & 56.8 \\
\hline $\mathbf{3 .}$ & $2: 00 \mathrm{PM}$ & 61.4 \\
\hline $\mathbf{4 .}$ & $2: 10 \mathrm{PM}$ & 74.2 \\
\hline $\mathbf{5 .}$ & $2: 20 \mathrm{PM}$ & 85.7 \\
\hline $\mathbf{6 .}$ & $2: 30 \mathrm{PM}$ & 85.1 \\
\hline $\mathbf{7 .}$ & $2: 40 \mathrm{PM}$ & 89.9 \\
\hline $\mathbf{8 .}$ & $2: 50 \mathrm{PM}$ & 89.7 \\
\hline $\mathbf{9 .}$ & $3: 00 \mathrm{PM}$ & 90.2 \\
\hline $\mathbf{1 0 .}$ & $3: 10 \mathrm{PM}$ & 88.6 \\
\hline $\mathbf{1 1 .}$ & $3.20 \mathrm{PM}$ & 87.3 \\
\hline
\end{tabular}

TIME VS TEMPERATURE

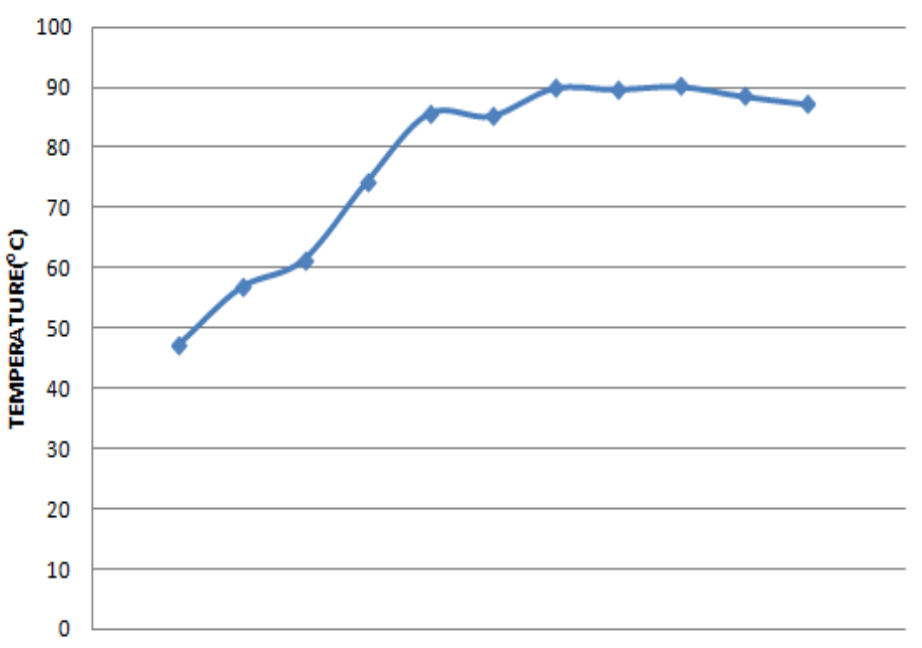

1:26PM 1:40PM 1:55PM 2:09PM 2:24PM 2:38PM 2:52PM 3:07 PM 3:21PM 3:36PM TIME(min)

Fig 5.3 Time vs Temperature of black coated cooker with paraffin wax

\section{RESULTS AND CONCLUSION}

Among the above experiments table 5.2 reads the maximum temperature of $94.1^{\circ} \mathrm{C}$. The following table 6.1 describes the maximum temperature that we have obtained from normal mirror reflection.

\begin{tabular}{|l|l|l|}
\hline Cooking vessel & $\begin{array}{l}\text { Maximum } \\
\text { temperature }\left({ }^{\circ} \mathbf{C}\right)\end{array}$ & $\begin{array}{l}\text { Time to } \\
\text { temperature(min) }\end{array}$ \\
\hline $\begin{array}{l}\text { Black coated pressure } \\
\text { cooker }\end{array}$ & 78.5 & 90 \\
\hline $\begin{array}{l}\text { PCM (Paraffin wax) } \\
\text { with stone pebbles }\end{array}$ & 94.1 & 190 \\
\hline PCM Paraffin wax & 89.9 & 120 \\
\hline
\end{tabular}

Table 6.1 Maximum Temperature reached time.

The size of the solar box reflecting mirror, we adopted is about $58 \mathrm{~cm}$ length, $28 \mathrm{~cm}$ breadth and $2 \mathrm{~cm}$ height. For this we obtain the maximum temperature of $94.1^{\circ} \mathrm{C}$.

\subsection{CONCLUSION}

Solar technology has made huge technological and cost improvements, but more research and development remain to be done to make it cost-competitive with fossil fuels. Costs can be reduced by increasing demand for this technology worldwide, as well as through component design and advanced systems.. Advancements in the technology and the use of low-cost thermal storage will allow future solar power plants to operate for more hours during the day and shift solar power generation to evening hours.

\section{REFERENCES}

[1] Design, development and testing of a double reflector hot box solar cooker with a transparent insulation material: N.M. Nahar, Central Arid Zone Research Institute, Jodhpur 342 003, India Received 21 July 2000; accepted 23 August 2000.

[2] Performance of solar cooker with two different pot materials: Dileep Varshney, Sanjay Kumar Srivastava and Ajeet Kumar rai Department of mechanical engineering, Siet, Shuats-Allahabad, UP, India.

[3] Performance Evaluation of a Solar Cooker with Low Cost Heat Storage Material: Abhishek Saxena, Mehmet Karakilcik, Department of Mechanical Engineering, Moradabad Institute of Technology, Moradabad, India Department of Physics, University of Cukrova, Adana, Turkey.

[4] A review on performance improvements in box type solar cookers: Chinnumol Francis, Victor Jose, P.G Student, Assistant Professor Amal Jyothi College of Engineering, Kanjirappally, Kottayam, Kerala, Email: 1chinnumolfrancis@gmail.com.

[5] Determination of thermal performance of a box type solar cooker: Sunil Geddam, G. Kumaravel Dinesh, Thirugnanasambandam Sivasankar $\Uparrow$ Department of Chemical Engineering, National Institute of Technology Tiruchirappalli, Tamilnadu, India.

[6] Thermal Energy Storage with Phase Change Material was published in Leonardo Electronic Journal of Practices and Technologies from Department of Mechanical Engineering, Technical University of Cluj-Napoca, Romania.

[7] Patil N.D., Design and Analysis of Phase Change Material based thermal energy storage for cooking purpose: a Review, International Journal of Engineering Science and Technology (IJEST), 2012. 